\title{
As TECNOLOGIAS TOUCH: CORPO, COGNIÇÃO E SUBJETIVIDADE
}

\author{
TOUCH TECHNOLOGY: BODY, COGNITION AND SUBJECTIVITY
}

TECNOLOGIAS TOUCH: EL CUERPO, LA COGNICIÓN Y LA SUBJETIVIDAD

Nize Maria Campos Pellanda*

Karla Rosane do Amaral Demoly**

\section{Resumo}

O artigo trata da preparação de um quadro teórico para suportar uma pesquisa empírica que usa as tecnologias touch com o objetivo de mobilizar cognitiva e afetivamente sujeitos portadores de patologias cognitivas, principalmente autismo. A estrutura epistemológica da pesquisa baseia-se na abordagem complexa defendendo a ideia da necessidade de articular dimensôes do humano que foram cindidas pela modernidade. Assim, partindo do pressuposto da unidade mente-corpo de Espinosa, as autoras passam por estudos recentes das neurociências e chegam até os estudos da biologia de cunho cibernético de H. Atlan, H. Maturana e F. Varela (teorias da "Complexificação pelo ruído" e da "Biologia da cognição") para mostrar a relação de tato com o dispositivo técnico integrando as demais dimensóes. $\mathrm{O}$ artigo resgata a tecnologia de seu "ressentimento" moderno para mostrar complexidade de um novo paradigma que vê no objeto técnico uma potencialização do humano.

Palavras-chave: tecnologias touch; autopoiesis; patologias cognitivas; complexificação pelo ruído; Biologia da cognição.

\section{Abstract}

This paper deals with the composing of a theoretical framework to support an empirical research that uses the "touch technologies" with the goal of mobilizing, cognitively and affectively, subjects with cognitive pathologies, mainly autism. The epistemological structure of the research is based on a complex ap-

\footnotetext{
* Universidade de Santa Cruz do Sul, Santa Cruz, RS/Brasil.

** Universidade Federal Rural do Semi-Árido, Mossoró, RN/Brasil.
} 
proach stressing the idea of the necessity of articulating dimensions of the human being that were severed in the modernity. Then, departing from of the assumption mind-body unity by Spinoza, the authors approach the recent studies of neurosciences, until the studies of biology in a cybernetic perspective by $\mathrm{H}$. Atlan, H. Maturana and F. Varela ("Complexification from the noisy" and "Biology of Cognition" theories) in order to show that the relationship between the touch and the technical object implies in integration of another dimensions. The article rescues the technology from the modern "resentment" to show the complexity of a new paradigm that sees in the technical objet a strengthen of the human being.

Keywords: touch technologies; cognitive pathologies; complexification from noisy; Biology of cognition.

\section{RESUMEN}

El artículo trata de la preparación de un marco teórico para apoyar la investigación empírica que utiliza la tecnología táctil con el objetivo de movilizar a los sujetos cognitivos y afectivos con trastornos cognitivos principalmente autismo. El marco epistemológico de la investigación se basa en el enfoque complejo abogando por la idea de la necesidad de articular las dimensiones humanas que se separó de la modernidad. Por lo tanto, teniendo en cuenta el concepto de la unidad mente-cuerpo de Spinoza, los autores pasan por estudios recientes de la neurociencia y alcanzan los estudios de biología de fuente cibernética de $\mathrm{H}$. Atlan, H. Maturana y F. Varela (teorías de la "complejidad por el ruido" y "biología del conocimiento") para mostrar la relación de contacto con el dispositivo técnico incorporando otras dimensiones. El artículo recoge la tecnología de su "resentimiento" moderno para mostrar la complejidad de un nuevo paradigma que ve el objeto técnico como una potenciación de lo humano.

Palabras clave: tecnologías táctiles; autopoiesis; trastornos cognitivos; la complejidad por el ruido; Biología de la cognición.

\section{O homem começa quando começa a técnica J. Ortega y Gasset}

\section{Introdução}

A cultura da fragmentaçáo que herdamos do cartesianismo levou à noção da separação mente/corpo. Esta fragmentaçâo específica, bem como as cisôes das 
dimensóes da realidade em geral, tiveram consequências dramáticas para a humanidade em termos da negaçáo do funcionamento dos seres humanos como um todo inseparável. Já no século XVII, Espinosa, contemporâneo de Descartes, numa abordagem complexa da realidade, contestou profundamente esta separação, mostrando um imbricamento profundo da mente com o corpo e o que isso significa em relação à constituição de cada ser humano. Isto teria implicaçóes significativas na compreensão sobre como conhecemos, como nos comunicamos, como produzimos a nós mesmos e a realidade. Este filósofo defendeu a ideia de integração de todos os níveis da realidade numa Substância Única (Espinosa, 2007).

Espinosa foi rejeitado pela grande maioria em sua época e esquecido por um longo tempo. O mundo contemporâneo viu nascer um interesse crescente pela obra espinosiana. Hoje, em tempos de complexidade, cientistas de ponta como o neurocientista Antonio Damásio e o médico/biólogo Henri Atlan, este último trabalhando com os pressupostos cibernéticos, resgatam os pressupostos espinosianos, colocando-os no coração de suas teorias. No centro deste resgate está a questão da unidade mente-corpo e uma visão holística da realidade.

Na perspectiva da complexidade, pensamos o corpo na sua interação com a tecnologia. Esta foi outra simplificação da modernidade, quando a técnica é pensada como separada dos humanos. Gilbert Simondon estudou com muita lucidez o "ressentimento" moderno em relação à tecnologia, enfatizando a atitude dicotômica homem versus técnica. Situa que os objetos técnicos integram-se ao mundo humano que eles prolongam. Traz-nos a noção de uma tecnoestética, ao explicar que "[...] uma ferramenta pode ser bela na ação, logo que ela se adapta bem ao corpo que ela parece prolongar de maneira natural e amplificar, de alguma maneira, seus caracteres estruturais" (Simondon, 1989, p. 186).

$\mathrm{O}$ autor alerta para duas posiçóes que considera reducionistas, uma que vê na cultura a possibilidade de humanização e na tecnologia o perigo da desumanização; outra que vê na presença dos objetos técnicos a organização material de algo que apresenta somente utilidades. Nos dois casos, temos a separação humano/máquina e uma redução dos objetos técnicos, posiçôes estas que revelam incompreensão da humanidade presente nas máquinas que inventamos. Para ele, é preciso compreender as relaçóes entre as açóes humanas e os objetos que as reconfiguram.

A alegria que se sente ao circular entre as construçóes novas é, ao mesmo tempo, técnica e estética. O sentimento técnico-estético parece ser uma categoria mais primitiva que o próprio sentimento estético, ou o aspecto técnico considerado sob o ângulo estrito da funcionalidade, que é empobrecedora (Simondon, 1998, p. 265). 
Henri Atlan discute a posição que privilegia as funcionalidades das tecnologias e analisa experiências de produçôes técnicas na área da saúde. O autor alerta para o equívoco da tecnocracia que faz o elogio a toda a potência da tecnologia, o que implica operar com a concepção utilitária, quando não reconhecemos os riscos de alguns procedimentos. Aponta que os sofrimentos com os quais convivemos devem ser elevados e combatidos por todos os meios que a ciência e a inteligência técnica podem colocar à nossa disposição (Atlan, 2006, p. 291-296).

A dimensáo humana dos objetos técnicos de que fala Simondon tem a ver com os significados deste objeto no sentido da ampliação dos potenciais humanos de conhecimento, de abertura para a invenção de formas de viver. Para este filósofo da técnica, tais atitudes dicotômicas, o elogio e o preconceito na relação com os objetos técnicos carecem de fundamento e, por aí, ele vai construindo sua teoria integradora, resgatando o papel constitutivo da técnica para o processo de subjetivação: "a tecnoestética não tem como categoria principal a contemplação. É no uso, na ação, que ela se torna de certa forma orgásmica, meio tátil e motor de estímulo" (Simondon, 1989, p. 259).

Na leitura da defesa que Simondon faz do objeto técnico (OT), encontramos uma postura complexa que nos mostra a técnica na sua dimensão epistêmica e ontológica de forma inseparável. Ou seja, a relação dos sujeitos com a técnica é uma relaçáo que os constitui em termos cognitivos. E, indo mais longe em relação a estas implicaçôes ontoepistêmicas, poderíamos arriscar como hipótese algo que é muito importante para a nossa pesquisa em andamento: uma criança com problemas cognitivos e de comunicaçáo pode vivenciar numa máquina digital os mecanismos de autorregulação e, por abdução, entender que ela própria também funciona assim, sendo capaz de autorregular-se.

Virgínia Kastrup (1999) amplia esta discussão ao dizer que:

A técnica não é somente o terreno dos objetos artificiais, mas potência de artificialização da cognição e de virtualização da inteligência. Não artificializa uma natureza dada, mas reverbera sobre a natureza da cogniçáo, natureza em si mesma artificiosa e inventiva, que a vida virtual prepara. Abre-se assim a possibilidade de pensar a cognição como híbrido de natureza e artifício (Kastrup, 1999, p. 183).

É interessante lembrar que Espinosa fazia um significativa analogia entre a técnica para fabricação de instrumentos e a técnica para pensar. Para ele, os humanos inventam instrumentos técnicos materiais, como também técnicas para pensar e, em ambos os casos, vão aperfeiçoando este instrumental. 
O corpo não é algo isolado num ser humano, mas é o instrumento que temos para nos acoplar com o ambiente e, assim, ir fluindo na vida. As afecçóes do corpo neste fluir vão nos constituindo como subjetividade. E é nesta mesma direção que ocorre a aprendizagem: como um acoplamento complexo com a realidade. A aprendizagem é sempre emergência.

Estas palavras iniciais servem para que possamos introduzir o tema deste artigo: por que a relação dos sujeitos com as tecnologias touch é carregada de emoçóes e tem como consequências transformaçóes cognitivas e subjetivas tâo evidentes? Pensamos basicamente em sujeitos com patologias cognitivas em geral e em sujeitos portadores de autismo, em particular.

O que nos levou, a nós autoras, colegas pesquisadores e bolsistas de Iniciação Científica de um grupo de pesquisa, cujo eixo é Educação e Complexidade ${ }^{1}$, a estudar a relação de crianças com iPad foi a constatação de algumas evidências muito marcantes com crianças de nosso convívio que têm demonstrado transformaçóes significativas, bem como os relatos informais de profissionais da psicopedagogia e psicólogos sobre resultados iniciais do trabalho com iPad com crianças com dificuldades de aprendizagem. Para isso, estamos iniciando um projeto de pesquisa que envolve como sujeitos crianças com patologias cognitivas, severas e leves, incluindo algumas crianças autistas. Este artigo não relata esta pesquisa, porque, como referido, o projeto apenas começa. Mas o objetivo principal deste texto é desencadear reflexóes, recortar algumas cenas iniciais da convivência com as crianças e fazer a sistematização de nossos estudos teóricos, para servir de sustentação à referida pesquisa. Inclui-se também, como parte deste objetivo organizador, a questáo de fundo da complexidade, pretendendo mostrar que o sujeito com dificuldades cognitivas importantes, o que envolve problemas de subjetivação, comunicação e corporeidade, pode ser afectado pela hibridização com um objeto técnico. Com isso, estaríamos nos afastando do projeto de purificação da modernidade, trilhando o caminho da hibridização humanos/máquinas, o que acreditamos carregar potencializaçôes importantes: epistêmicas, ontológicas e comunicacionais (Latour, 2000).

\section{As tecnologias numa concepção ampliada}

O Paradigma da Complexidade que vai substituindo aos poucos o paradigma moderno da linearidade constituiu-se, em grande medida, pelo movimento cibernético dos anos 40 e 50 . Este movimento desdobrou-se em várias etapas, cada vez mais complexas, mas desde o seu início ficou assentada a importância 
do princípio de auto-organização e uma visão complexa da tecnologia. Seres vivos e natureza eram abordados com os mesmos princípios lógicos e não eram considerados como dimensóes diferentes da realidade. A mente passa a ser objeto empírico da ciência, deixando de ser especulação, como até então.

Para Espinosa, em seu pensar complexo, o corpo é uma máquina que reproduz no seu funcionamento modal a natureza mais ampla da qual é parte inseparável. Ele compara o processo de construção do conhecimento com a fabricação de objetos dizendo que "[...] a inteligência pela força natural fabrica para si instrumentos intelectuais" (Espinosa, 2007, p. 20).

Nossa abordagem da técnica, portanto, é complexa. Como Simondon (1989), queremos pensar a técnica como inseparável da cultura e do próprio processo de devir do ser humano, sem a negação da realidade técnica como uma realidade humana. Para o autor, a técnica foi considerada, na nossa cultura, estranha ao humano e, neste sentido, despojada do potencial de significação. E é exatamente por aí que pretendemos caminhar nos nossos argumentos, para podermos chegar a operar num acoplamento tal dos sujeitos cognitivos portadores de patologias cognitivas com o iPad, observando os processos de significaçáo/ conhecimento/subjetivação aí envolvidos. Acreditamos que o iPad pode ser um objeto estético, na medida em que serve como um instrumento de construção de si, através das significaçôes que podem gerar autorreconfigurações.

No referido movimento cibernético vamos encontrar von Foerster (1996) falando de máquinas triviais e não-triviais e, na senda por ele aberta, encontramos Maturana e Varela referindo-se a máquinas alopoiéticas e máquinas autopoiéticas (Maturana \& Varela, 1980).

Von Foerster em suas valiosas contribuiçōes à Segunda Cibernética fez uma distinção entre "máquinas triviais" e "máquinas não-triviais" para destacar os vivos como máquinas autorreguladoras. As máquinas triviais trabalham com regras fixas em termos do princípio do estímulo-resposta e dependem de um operador externo. As máquinas não-triviais, pelo contrário, são aquelas que possuem um dinâmico estado interno, capaz de se automodificar de acordo com as perturbações de forma não-previsível, apresentando novidades. Mas a ideia de máquina está sempre presente, sem que seja estranha ao humano e, mesmo, ao vivo.

Essas elaboraçóes permitiriam que, mais tarde, von Foerster fizesse ampliaçóes de seu sistema de pensamento para pensar as questóes do conhecimento e a educação (von Foerster, 1996).

Uma das marcas das práxis educacionais tradicionais é a trivialização do ensino. Essa atitude não é inócua, porque toca em aspectos constituintes do humano, como as questóes de formular problemas e autonarrativas como meca- 
nismos de autoconstituição e de automobilização. Von Foerster, falando de um ponto de vista cibernético, e os seres vivos são cibernéticos, na medida em que se autorregulam, coloca que o ensino tradicional se constitui num processo de trivialização. As máquinas entram no processo educacional apenas como instrumentos pedagógicos de apoio e, raramente, como dispositivo de acoplamento. A expressão "uso de tecnologias" se faz presente e, concordamos com Simondon, faz pensar em termos da separação humano/máquina. Os efeitos do encontro de crianças autistas com o iPad, as operaçôes que realizam na interação ajudam a compreender que neste encontro temos uma reconfiguraçáo dos processos cognitivos. Deslocamentos e transformaçóes acontecem nas experiências de crianças autistas no acoplamento com as diferentes funcionalidades que o objeto oferece. Para Simondon, quanto mais complexa uma máquina, mais aberta e com potencialidades de humanização, de reconfiguração da experiência humana.

Nossa questão com o uso do iPad é justamente destrivializar a relação da criança com os instrumentos pedagógicos, oferecendo elementos perturbadores para mobilizar a autorregulação.

Na mesma lógica, como vimos, Maturana e Varela falam de máquinas alopoiéticas e máquinas autopoiéticas. É interessante lembrar aqui que estes dois biólogos cunharam o conceito de Autopoiesis como elemento teórico central da teoria cibernética da Biologia da Cognição. Estes pesquisadores se debruçaram sobre uma questáo central que foi a de explicar o que possuem os sistemas viventes que nos permitem qualificá-los como tal. Autopoiesis é um conceito criado pelos autores para dar conta do fenômeno do viver, para explicar fenômenos moleculares, o operar em organismos moleculares. Os humanos vivem a mesma dinâmica molecular. A expressão é de origem grega e significa: auto - por si e poiése - produção, o que implica pensar que o viver sucede autoprodutivamente nos organismos vivos. Autopoiesis refere-se à dinâmica circular autoprodutiva dos organismos vivos, diferenciando-os dos não-vivos. A vida se mantém pela dinâmica autopoiética e pela congruência ao meio; a perda de uma ou outra pode levar a processos destrutivos.

Maturana (2004) esclarece que se pode usar o conceito de autopoiesis nas circunstâncias relacionadas com a conservação do viver. Para que a vida siga se diferenciando, há necessidade de conservar a autopoiesis e a congruência ao meio. $\mathrm{O}$ fluir do viver é uma deriva, como um timoneiro que náo controla o barco, muda o curso do barco diante de novas circunstâncias que podem surgir.

Com o conceito de autopoiesis estes cientistas expressam a característica básica dos seres vivos que é a autoprodução. Então, as máquinas alopoiéticas seriam aquelas máquinas que dependem de algo externo para seu funcionamento inicial, 
produzindo coisas que são diferentes de si mesmas. Por exemplo, uma máquina de Coca-cola produz algo que é diferente da própria máquina. Ao contrário, as máquinas autopoiéticas (seres vivos) produzem a si mesmas ao operar no viver (Maturana \& Varela, 1980).

Em tempos de complexidade, Pierre Lévy foi um dos filósofos mais significativos a pensar a técnica de forma complexa, ou seja, em forma de acoplamento estrutural constitutivo de subjetividade. Inserido no novo paradigma, ele assim se expressa:

A ciência clássica excluía do universo físico a história e a significação para recalcá-las nos seres vivos, ou mesmo em um único sujeito humano. Mas diversas correntes científicas contemporâneas redescobriram uma natureza na qual seres e coisas não se encontram mais separadas por uma cortina de ferro ontológica (Lévy, 1994, p. 136).

Com esta posição, Lévy formula o conceito de "ecologia cognitiva", que são as interaçóes entre seres humanos e tecnologias, formando um sistema auto-organizado do qual emergem os processos de subjetividade. Trata-se de um "mundo matizado" e não mais purificado com as rígidas separaçóes entre sujeito e objeto (Lévy, 1994, p. 213).

Guattari capta muito bem esta questão:

O que importa aqui não é unicamente o confronto com uma nova matéria de expressão, é a constituição de complexos de subjetivação: indivíduo-grupo-máquina-trocas múltiplas que oferecem à pessoa possibilidades diversificadas de recompor uma corporeidade existencial, de sair de seus impasses repetitivos e, de alguma forma, de se re-singularizar (Guattari, 1992, p. 17).

Para a abordagem complexa que estamos defendendo, estas aproximaçóes são estratégicas.

A noção complexa de tecnologia como autoconstituição já está em Espinosa. O conceito de Substância Única compreende infinitos modos que seria cada ser vivo. Cada um de nós é um modo da Substância Única que a modifica através de seus atributos. Nestas modulaçóes de cada ser vivo há implícita toda uma tecnologia do humanizar-se.

Ortega y Gasset, no melhor estilo autopoiético, fala da "Vida como fabricação de si mesma” (Ortega y Gasset, 1963, p. 43). Neste sentido, ele chega mes- 
mo a falar de "técnicas da alma". Para este filósofo da técnica que não simplifica ao falar desta temática, a modernidade abordou a técnica de forma simplificadora. Diz ele:

As respostas que se deram à pergunta - o que é a técnica? - são de uma pavorosa superficialidade. E o pior do caso é que não se pode atribuir ao acaso. Esta superficialidade é compartilhada por quase todas as questóes que se referem verdadeiramente ao humano no homem. E não será possível pôr alguma clareza nelas se não nos resolvemos a tomá-las no estrato profundo onde surge todo o propriamente humano (Ortega y Gasset, 1963, p. 35).

Sherry Turkle, pesquisadora do MIT (Massachusetts Institute of Technology), pesquisa a relação sujeito/computador desde os inícios do computador pessoal. Numa fase em que o computador era ainda um objeto mais "tosco", comparando com as máquinas cada vez mais amigáveis que foram surgindo o longo do tempo, Turkle dizia já no início da década de 90: "O que me atrai no computador são as possibilidades de conversar” (Turkle, 1997, p. 30). E ela incluía este conversar num sistema onde os sujeitos e as máquinas formavam um todo complexo, no qual os sujeitos se transformavam porque o computador era um "objeto para pensar com”. Ela pensa, portanto, “[...] sobre como as intensas relaçóes entre as pessoas e os computadores ocorrem e como estas relaçóes estâo mudando a maneira como elas pensam e sentem". Para ela, "o computador pode ser experimentado como um objeto na fronteira entre o self e o náo-self" (Turkle, 1997, p. 22-30).

Os objetos técnicos digitais foram evoluindo, através das últimas décadas, no sentido de uma arquitetura cada vez mais plástica, o que oportuniza uma relação mais flexível e provocativa com aqueles que experimentam formas de linguajar neste acoplamento, processos potencializadores de autoconstituição.

\section{"Náo se sabe o que pode o corpo" ou Tecnologias touch e o cérebro na ponta dos dedos}

"Não se sabe o que pode o corpo" (Espinosa, 2007, p. 178).

Focamos agora nas crianças autistas. Os estudos sobre autismo são inúmeros e, apesar disto, não se tem hoje um consenso sobre a gênese desta síndrome. $\mathrm{O}$ que existe é uma tendência de concordar sobre os sintomas destes sujeitos em termos de dificuldades de comunicaçáo, de autoexperimentação e de aprendizagem. 
As palavras iniciais de Espinosa, bem como o conceito de autopoiesis, podem nos ajudar na nossa proposta de atividades com as crianças autistas. Se estas crianças têm um acentuada dificuldade de autoconstruçáo e, portanto, de autonomia e de acreditar na sua própria autoria, é importante pensarmos em atividades em que elas possam se autoexperimentar a partir do corpo. Deleuze, ao pensar o que significa conhecer em Espinosa, faz referência a um processo vivo carregado de "perceptos" (novas maneiras de ver e ouvir) e de "afectos" (novas maneiras de sentir) (Deleuze, 1992). Com isto, poderíamos pensar num dispositivo técnico (aplicativos do iPad) que oportunizasse a crianças com patologias cognitivas, ou mesmo com autismo, a tentar novas formas de autoexperimentação.

Experimentar, inventar algo é o que nós os seres humanos fazemos no linguajar. Uma cena mostra momentos iniciais de nossa pesquisa e permite compreender este conceito no operar cotidiano de uma das autoras deste trabalho:

A mãe de uma criança sobe a escada de mãos dadas com seu filho, menino com olhar vibrante que chamaremos de UV. Ao espiar pela porta, UV começa a puxar sua mãe para descer. Observo e ela diz, "não tem os computadores, ele imaginava que sim". Vou até UV e o convido para entrar dizendo que temos ali outras máquinas, o iPad.

Ele vem até a porta, estende as mãos e senta diante do iPad. Soubemos depois que desconhecia este equipamento. Rapidamente esta criança começa a explorar o iPad, encontra a rede e digita o nome de um programa "CQC", jornalismo com humor. Escutamos o diagnóstico que é feito pelas colegas que trabalham com esta criança, "autismo grave". UV conecta através da escrita no link que aponta para o YouTube, sabe ler e escrever. Assiste a este programa de um modo diferente, num vai e vem, sempre a repetir, neste momento. O programa traz cores, sons, movimento e risos, envolvendo esta criança (Cenas do percurso comentado no $1-U V-31$ mai. 2012).

Procuramos observar com atenção os movimentos de UV para descobrir as pistas que indicam, neste caso, necessidade nossa de conhecer o programa e explorar suas possibilidades no momento seguinte. O contrário disto é o que muitas vezes encontramos nos espaços da educação, quando uma criança toma um objeto para criar algo e dizemos para parar, na ilusão de que existe algo mais importante do que o fazer e os afectos no ato de tomar um objeto técnico, gestos envolvidos, sentimentos e conexóes que ali se produzem consigo e com o mundo. Tínhamos pensado em propor jogos, aplicativos que favorecem a conversação, 
mas UV, logo que tomou o iPad, buscou rapidamente este programa. Precisávamos iniciar por este ponto de contato com ele.

Se o ser vivo é autopoiético, no sentido de que produz a si próprio no viver, intervençôes do tipo autopoiético podem ser afectantes, na perspectiva espinosiana. Trata-se de trabalhar com emergências, com genealogias e não com coisas prontas. É o que estamos experimentando.

UV realiza movimentos que se repetem no primeiro encontro, o que sabemos que é um sintoma dos sujeitos em circunstância de autismo. Diante da pergunta sobre por que gosta deste programa, a criança usa suas mãos para afastar, mostra-se tranquila, como se este programa a afectasse provocando este sentimento. Deparamo-nos com a força desta ferramenta em que o toque faz percorrer caminhos, surpreender-se, sentir, o que Simondon designa como "fruição estética". Novo encontro em que observamos o envolvimento das crianças com o iPad e suas açôes no ambiente, de onde recortamos o que UV experimenta.

UV entra na sala já procurando pelo iPad, inquieta-se diante da dúvida, se vai encontrá-lo ou não. $\mathrm{O}$ olhar fixa os diferentes objetos, máquinas fotográficas, notebooks, mas UV desloca rapidamente para o iPad. Fica novamente a assistir o programa CQC do seu modo, abre e fecha diferentes partes gravadas deste programa no YouTube, começa a assistir e fecha, abre novamente. $\mathrm{O}$ som, as cores e as risadas o animam. Sua máe havia comentado que UV começa a deslizar os dedos na tela do computador, como a pedir para ter um iPad em casa.

UV sempre focado no iPad, o convido a conhecer outros programas, jogos, ele entende e afasta com suas máos o meu corpo da mesa, como a dizer, "deixa eu aqui...". Após certo tempo e estas atitudes repetidas, ele passa a interagir com outros vídeos no iPad, os vídeos se referem a programas de televisão, onde estas características de luzes, sons e cores estão presentes. Já próximo do término deste encontro, UV fecha os vídeos e começa a explorar a interface em que temos as imagens de jogos e aplicativos que baixamos porque favorecem formas de conversação e de interação. Em um primeiro momento, abre e fecha jogos e faz uma exploração global, sem focar um jogo em particular. Quando dizemos que está na hora, UV, assim como outras crianças, permanece interagindo, até que me aproximo e digo a ele que seguiremos na semana seguinte. UV se despede porque eu digo tchau, chamo sua atenção e o olhar se volta para mim. Ele coloca a mão na boca e faz o gesto de mandar um beijo (Cenas do percurso comentado $\mathrm{n}^{\circ}$ 2 - UV - 07 jun. 2012). 
Sob o ponto de vista neurológico, as operaçóes cognitivas disparadas pelo toque da ponta dos dedos podem levar a configuraçóes neurofisiológicas, ativando regiốes do cérebro até entâo menos ativas. Para Damásio, o tato discriminativo é uma forma de elaborar o conhecimento do mundo exterior. Para este neurocientista:

Seus sinais refletem as alteraçóes sofridas na pele por sensores especializados, quando temos contato com outro objeto e investigamos sua textura, sua forma, seu peso, sua temperatura, etc. Enquanto a divisão do meio interno e das vísceras se ocupa em grande medida da descrição dos estados internos, a divisão do tato discriminativo se dedica sobretudo à descrição de objetos externos com base nos sinais gerados na superfície do corpo (Damásio, 2000, p. 200).

Os gestos de uma criança diante do computador envolvem o teclar e aqui temos um teclado como intermediário entre o dedo e o objeto. Já quando está diante do iPad, temos o toque direto na tela, o que poderá trazer implicaçóes neurofisiológicas. Ora, este mecanismo está relacionado com o pressuposto de Espinosa de que o corpo é a ideia que a mente tem do corpo (Espinosa, 2007).

O corpo é afectado por objetos externos e se transforma e a mente mapeia estas afecçóes. E entendemos mente como processo e não como coisa (Damásio, 2003). O corpo opera transformaçôes no modo de esta criança estar conosco no ambiente equipado com iPad, pouco a pouco UV desloca de movimentos repetitivos, que são importantes, passando a descobrir possibilidades de conexão consigo e com o ambiente sensível que organizamos para os encontros com ele.

Jean Paul Thibaud (2004), em seus estudos sobre as inscriçóes que realizamos no espaço habitado, refere-se ao ambiente sensível, ambiente que emerge enquanto lugar encarnado que se produz junto conosco, no tecer das açóes que experimentamos no encontro com os outros e no acoplamento com diferentes objetos técnicos. A percepção do que se experimenta neste ambiente sensível nos remete a emoçóes, gestos, inscrições em que UV mostra os efeitos da tecnologia, aqui no sentido da conexão consigo mesmo e com o ambiente. Em nossa experiência, esse caminho permite a observação de transformaçóes que emergem na convivência, quando esta criança opera com formas de linguajar no encontro com o iPad em um espaço de conhecimento.

UV começa a brincar com os animais que emitem sons a partir do toque de suas mãos. Experimenta o toque no gato e as reaçóes que o próprio 
aplicativo oportuniza; a cada toque, o gato ou o cachorro fazem algo como dormir, pular, etc. Começo a brincar com ele e a falar cumprimentando, perguntando, pois os animais fazem gesto colocando a mão ao redor do ouvido, como que a dizer que não estão ouvindo. Faço isto para sugerir que também fale ou responda e, assim, o gato que está na tela vai reproduzir sua voz. UV não fala, mas faz um gesto em que toca em meu braço como a pedir que eu fale novamente, quer que eu continue a mostrar. A interação com o aplicativo opera mudança em que UV interage comigo. Quando toca no meu braço e aponta para a interface sabe o que quer realizar. Depois de certo tempo, ele fecha este jogo e descobre a câmera no iPad, começa a se ver e a fazer movimentos com as mãos. Ao clicar na câmera, experimenta a foto. Faz movimentos com o rosto e com as máos, olha para a câmera e segue experimentando os gestos e sua visualização na interface do iPad. Permanece até o final do encontro nestes movimentos de ver-se diante da câmera e a observar os próprios gestos que realiza (Cenas do percurso comentado no 3 - UV - 14 jun. 2012).

O gesto de alegria se mostra quando esta criança sorri e bate os dedinhos na mesa, o corpo vibra. UV compreende o que falamos, toma o iPad e define rapidamente o que quer experimentar, o jogo que o engaja, permanece ali interagindo, se póe a brincar. Esta criança busca conhecer jogos, surpreende-se com o que surge na tela, como efeito das vozes do ambiente e dos gestos diante da câmera que permite fotografar e filmar. Observamos que UV escreve o que quer buscar, fazer. Imagens e sons atraem e reconfiguram modos de escrever e interagir. Esta criança não fala conosco, mas sentimos que está em contato com formas de linguajar que elege. Imaginamos como será quando interagir com aplicativos que convidam a conversar que são desenvolvidos por pesquisadores da computação, justamente a partir desta questão de como favorecer o ato de fala.

O coletivo de pesquisadores envolvidos nesta experiência compreende a intensidade do que coloca Humberto Maturana, ao referir às emoçóes que sustentam os fazeres humanos na linguagem, pois sentimos e percebemos que é a amorosidade envolvida na experiência que produz o acolhimento da diferença, a alegria de estar juntos a aprender sobre as formas de habitar este nosso mundo. Processos cognitivos-subjetivos como o que experimenta outra criança aponta para a intensidade deste conceito. Diferente de UV, a criança que chamaremos de EM faz pensar em como podemos buscar pontos de conexão, quando o olhar, os gestos e sentimentos parecem endereçar para lugar algum. 
EM entra na sala, caminha em direção à janela e toma nas mãos as pontas de uma cortina, busca morder. Neste momento, me aproximo, digo meu nome e pergunto o seu. Nenhuma resposta, o corpo se move neste primeiro contato como se EM não percebesse a minha presença. Depois de repetir várias vezes o gesto de tomar as pontas da cortina e procurar morder, olha para trás, como que a sentir a minha presença ao seu lado, o olhar se mantém fixo dirigido à cortina. Larga a cortina, as demais crianças estão sentadas nas cadeiras, EM senta no chão, pega a tampa de um lixinho pequeno e começa a girar esta tampa, seus olhos acompanham o movimento repetidas vezes. Me ponho a pensar sobre o estar no chão, enquanto EM, depois de certo tempo, levanta. Mostra-se inquieto, senta novamente no chão e começa a mexer seus próprios dedos, a brincar ou a movimentar, como que estivesse contando, parece brincar com seus próprios dedos. Não olha para as outras crianças que exploram o iPad (Cenas do percurso comentado no 1 - EM - 31 mai. 2012).

Como estabelecer uma conexão com esta criança que parece não perceber o espaço ao seu redor, as outras crianças e os bolsistas da pesquisa? É preciso buscar formas de aproximação. Deleuze e Guatarri indicam a imprevisibilidade das conexóes que produzimos no cérebro no percurso de nossas vidas como seres humanos. O grande desafio na convivência com EM passa a ser o de trazer possibilidades e observar com atenção para descobrir as pequenas pistas que, pouco a pouco, mostra, indicando que são necessárias de serem tomadas na experiência. Discursos surgem de diagnósticos realizados sobre EM: "autismo severo e dificuldades de permanecer muito tempo em atendimento, não mais do que 10 minutos". A criança, mesmo sem tomar qualquer objeto, permanece 45 minutos conosco e, neste momento inicial, buscamos conexáo. Deleuze e Guatarri discutem as diferentes conexóes e a potência do ser humano, o que ajuda a compreender sobre as formas de agir e conviver no ambiente com esta criança autista:

O pensamento não é arborescente, e o cérebro não é uma matéria enraizada nem ramificada. Aquilo a que chamamos, injustamente, "dendritos" não asseguram uma conexão dos neurônios num tecido contínuo. A descontinuidade das células, o papel dos axônios, o funcionamento das sinapses, a existência de microfendas sinápticas, o salto de cada mensagem por sobre essas fendas, fazem do cérebro uma multiplicidade que mergulha, em seu plano de consistência, num sistema de incerteza probabilística, uncertain nervous system (Deleuze, G., \& Guatarri, F. 1996, p. 25). 
Ainda neste primeiro encontro com EM, um deslocamento se produz quando sentimos que estabelecemos um laço de conhecimento na experiência do brincar.

EM segue manipulando e olhando para seus próprios dedos. Me vem a ideia de brincar com ele, entrar neste jogo. Sento no chão ao seu lado, faço o mesmo, brinco com os dedos de uma das máos e a coloco diante dos seus olhos. Ele para, olha para o lado, fita meu olhar, pega seu dedinho e aproxima do meu rosto. Imagino que sejam os óculos e o costume de crianças quererem pegar, mas não. Ele encosta os dedinhos no meu rosto, na ponta do nariz e depois faz um carinho na face, me abraça (Cenas do percurso comentado $\mathrm{n}^{\circ} 2$ - EM - 31 mai. 2012).

Podemos sentir e pensar sobre este modo de contato, como se ali EM tivesse percebido a presença do outro e o investimento para que possa estabelecer contato em um modo de linguajar escolhido por ele. Este investimento implica todo um emocionar que distinguimos na experiência com crianças que se mostram na diferença. Maturana indica que as emoçóes são perceptíveis no linguajar, porque todas as ações "surgem e são realizadas em algum domínio emocional" (Maturana, 2001, p. 129). O autor sugere que basta observarmos os fazeres cotidianos para identificar as emoçóes que vão modulando os distintos linguajares:

Nós sabemos pela nossa vida humana cotidiana que, ao nos movermos de uma emoção para outra, mudamos nosso domínio de ações, e isto vemos como uma mudança de emoção. Em outras palavras, é a emoção sob a qual agimos num instante, num domínio operacional, que define o que fazemos naquele momento como uma ação de um tipo particular naquele domínio operacional. Por este motivo, se queremos compreender qualquer tipo de atividade humana, devemos atentar para a emoção que define o domínio de açóes no qual aquela atividade acontece e, no processo, aprender a ver quais ações são desejadas naquela emoção (Maturana, 2001, p. 30).

As emoçóes configuram modos de estarmos na linguagem, e a emoção do "amor", como indica Maturana em sua perspectiva autopoiética, configura um modo de estar com o outro em confiança. É nesta direção que buscamos aproximar esta criança de objetos, jogos que permitam a interação e, nas escritas do percurso, podemos observar pequenos deslocamentos e transformaçóes: 
As crianças tiram fotografias e escolhem algumas para compor uma apresentação que projetaremos ao final. EM quer brincar durante quase toda a oficina com os fantoches que já estavam ali no ambiente, enquanto as demais crianças operam com o iPad ou com notebooks. Uma profissional da instituição ressalta algo, como que para indicar um crescimento, o fato de EM permanecer tranquilo conosco, experiência nova para ela. Eu pego um iPad que está sob a mesa e levo até EM, o convido a brincar, ele pega e faz movimento de colocar o iPad na boca, digo que não é para comer, que ele pode conhecer, mexer na máquina. EM vira e eu cuido apenas para que não deixe o iPad cair no chão, toca na tela e depois me devolve pedindo para ir embora, pois faz o gesto de pegar na minha mão e levantar, dirigindo-se até a porta (Cenas do percurso comentado no 3 - EM - 07 jun. 2012).

Esta criança se transforma em várias dimensões, pois manifesta a alegria de estar ali, permanece mais tempo no encontro e toma um objeto diferente da tampa de lixo que tanto o atraía. Assim como nos coloca Derrida, os acontecimentos podem nos afectar de um modo sensível, o que permite pensar de que produz para as crianças um prazer estético que abre possibilidades para o trabalho da pesquisa.

Ora, é difícil conceber um vivo a que ou para que alguma coisa acontece sem que uma afeição venha se inscrever de modo sensível, estésico, e mesmo algum corpo ou alguma matéria orgânica. Por que orgânica? Porque não existe o pensamento do acontecimento, parece, sem uma sensibilidade, sem um efeito estético e alguma presunção de organicidade viva (Derrida, 2001, p. 35).

Seguindo em novo encontro com EM, podemos observar alguns acontecimentos neste ambiente sensível em que nos deparamos com efeitos estéticos referidos por Derrida, acontecimentos em que nos movemos abertos para circunstâncias não previstas, pois estas são as que implicam em mudanças nas condutas das crianças, ao coordenarem fazeres neste linguajar no iPad.

EM se aproxima do iPad, faz o movimento de tocar os dedos deslizando. Repete varias vezes sem interromper, ele está explorando a ferramenta. Depois deste fazer, eu o convido para brincar e pergunto se quer escolher um jogo. Esta criança fica parada a olhar o iPad. Digo então que vou abrir o jogo em que aparece um gato e um cachorro, ela fica como que aguardando. Ao abrir o jogo, ela coloca os dedos, descobre as reaçóes do gatinho. $\mathrm{O}$ olhar parece não indicar nada, mas acontece de permanecer olhando a tela. 
Volta a operar com o iPad deslizando os dedos para lá e para cá. Depois de várias vezes, levanta, eu deixo o iPad na mesa, EM quer sair e eu o levo até sua mãe (Cenas do percurso comentado no 4 - EM - 14 jun. 2012).

Ficamos todos felizes, é uma grande transformação esta ação de já tomar máquinas para linguajar, nos emocionamos com EM. Circunstâncias de autismo como a que ele mostra nos desafiam a operar com este acoplamento com o objeto técnico iPad, seu modo de existência para citar expressão de Simondon, que aporta toda uma complexidade e abertura necessária quando investimos na potência do humano. Dimensóes do humano como a inteligência se mostram como efeito de perturbaçóes que emergem da experiência do convívio apoiado por ferramentas que permitem o linguajar com imagens, sons, vídeos, formas de escritura. Nesta perspectiva, todos nós os seres humanos somos capazes de conhecimento e aprendizagem, sem distinção aqui, apenas o que ocorre é que os caminhos são diferentes, pois se referem a cada sujeito, às circunstâncias que o levam a habitar o mundo de um jeito ou de outro. Estes caminhos procuramos compreender nas escritas do percurso.

EM entra na sala, sorri, caminha. Seu olhar parece não apontar lugar algum. Faz menção de pegar a cadeira, agora giratória, pois recebemos bancadas que são mesas e cadeiras bem confortáveis. Ele senta e começa a girar rapidamente, procura segurar em alguém para adquirir velocidade e girar. $\mathrm{O}$ convido a jogar, estico as mãos e ele se mostra agitado. Pensei em algo, ele havia faltado semana anterior devido a gripe forte... a sala está diferente. EM segue procurando girar a cadeira e eu o acompanho deixando-o explorar porque me parece que a cadeira é objeto novo e ele quer explorar. Depois de muito girar EM para e o convido para brincar no iPad, vem até a mesa onde está o iPad, fica parado diante da tela. Insisto dizendo, "Coloca seu dedinho ali, vais ver que legal!". EM encosta o dedo e diz "Pá". Ele fala algo, me emociono com ele. Resolvo tocar na câmera que é o que ele vê na interface e digo o mesmo "Pá". EM olha para si mesmo, sorri, começa a balançar a cabeça para lá e para cá, coloca as mãos na cabeça e observa a si mesmo na interface do iPad (Cenas do percurso comentado no 5 - EM - 28 jun. 2012).

Estamos diante de uma criança que começa a brincar tomando nas mãos um objeto técnico em nível de elaboração complexa como o iPad. EM sorri e permanece, como todas as demais crianças, até o final no tempo definido para o encontro.

Temos aqui crescimento e conhecimento, estando apenas no início de uma caminhada de pesquisa. A cada encontro percebemos a potência deste movimen- 
to de experimentar-se no acoplamento com o iPad. Enquanto pesquisadores, estamos a conviver com este "estranho em nós mesmos" no dizer de Julia Kristeva, quando realizamos esta imersão na pesquisa com jovens em circunstância de transtorno global de desenvolvimento (Kristeva, 2001).

Nestes momentos iniciais, temos elementos que reforçam nossa hipótese de pesquisa de que o iPad, enquanto objeto técnico, pode favorecer processos cognitivos que trazem como efeitos para as crianças a reconfiguração de formas de linguajar e de habitar os espaços do social.

A rede teórica que sustenta esta pesquisa considera um modo de conceber a tecnologia como integrada a experiência humana desde que nos constituímos como tal na linguagem. Goody (2007, p. 193) sustenta duas hipóteses que definem o problema: a de que o humano surge com a linguagem e a de que o modo de comunicação verbal implica no surgimento de uma tecnologia. Então, desde o princípio, tudo o que fazemos ocorre no acoplamento com tecnologias com que fomos inventando modos de viver e de conhecer.

Assim, podemos pensar a comunicação verbal como uma espécie de ferramenta, na medida em que é constitutiva do modo como conhecemos, isto é, de certa forma modifica as próprias formas de conhecer. Inicia-se com a linguagem um processo de transformação nos modos de comunicação e de conhecimento. Esta transformaçấo constante vem acompanhada da criação de máquinas de manipulaçáo simbólica e, nos diferentes modos de acoplamento do humano com as máquinas projetadas, observa-se a estruturação de processos cognitivos. Avançamos a tal ponto de produzir o iPad, objeto com alto nível de sofisticação e complexidade, o que remete ao que aprendemos com Simondon: quanto mais complexo o objeto, mais aberto e com potência de transformaçáo do humano neste acoplamento (Simondon, 1989).

Estamos continuamente tecendo redes de conversaçóes, redes que se tecem no entrelaçamento do linguajar e do emocionar e, enquanto seres vivos humanos, nos transformamos continuamente e temos diante de nós o compromisso da invenção das formas como vivemos. $\mathrm{O}$ modo como dirigimos a nossa atenção é distinto, porque observamos gestos, emoçóes, palavras, inscriçôes que afirmam esta condição humana de transformação contínua de si e do conhecimento. Sobre nossa dimensão humana e a potência que isto implica, afirma em forma de poesia Maturana, durante curso realizado em Santiago do Chile:

Único eres ser humano, entre todos los animales terrestres, que puedes soltar tus certidumbres en cualquier momento y dejar que la biología del amor te guíe, o enajenarte en ellas destruyendo tu libertad reflexiva. 
Único eres, ser humano, que en la reflexión puedes ser responsable, libre ético en tu vivir. Pero en esa unicidad tuya, eres una anomalía al menos en la biósfera terrestre que cursa sin sentido en un devenir en el que reflexión, libertad y ética no entran hasta que tú apareces (Maturana, escrita entregue durante curso em Santiago do Chile, 2005).

Mario Osório Marques (1999) se refere à materialidade das operaçóes do linguajar, operaçóes que envolvem um corpo, materializadas porque se efetivam e se transformam com tecnologias, aspecto importante em nosso trabalho. $\mathrm{O}$ autor também interroga o fazer educativo, muitas vezes distante destas construçôes novas, produzindo, assim, sofrimento e impedimentos de aprendizagem.

A partir do pressuposto de que na linguagem fazemos nosso mundo de homens e nela nos fazemos, materializada, encarnada em corpos que se movem nos vastos campos do significante, do imaginário radical, do simbólico, percebemos distintas linguagens correlacionadas em suportes corpóreos específicos e cada qual lançando peculiares desafios à escola e, mais precisamente, às relaçóes pedagógicas em sala de aula (Marques, 1999, p. 17).

Procuramos expandir nosso olhar quando observamos crianças na interação com o iPad. Isto porque modos de conhecimento se transformam e estas mudanças todas se mostram nas diferentes dimensôes do viver das crianças.

\section{Caminhos que se abrem}

O iPad enquanto objeto técnico proporciona este entendimento do operar dos sujeitos sempre no acoplamento com tecnologias, neste caso um objeto que produz a junção nesta relação corpo-máquina. Ao atingir um nível alto de tecnicidade, esta máquina torna-se mais aberta e o conjunto de máquinas abertas inventadas supóe os sujeitos como organizadores permanentes que, ao experimentarem, desencadeiam transformaçôes afectivas e cognitivas.

Temos uma nova circunstância para o trabalho e a convivência com crianças que apresentam transtorno global de desenvolvimento. O iPad é um dispositivo concreto para afectar e ser afectado, conforme pudemos observar nas cenas iniciais do percurso com UV. Entender a subjetivação como fluxo e o conhecimento como a capacidade de ser afectado implica pensar que o objeto técnico como o iPad se constitui como dispositivo de afecção. E o touch afecta corpo/ 
mente. Quando uma criança autista reage ao iPad é porque foi afectada física e mentalmente. Nesta circunstância, é provável que alguma área do cérebro foi ativada, o que não podemos mapear nem provar, porque não é do escopo deste trabalho, mas algum cientista da neurociência pode realizar, como desdobramento desta pesquisa.

Nosso trabalho se encontra em seu momento inicial, quando organizamos uma rede de sustentação teórica que dê conta de um modo complexo para abordagem de graves problemas que vivemos no social. Crianças e jovens em circunstância de transtorno global de desenvolvimento já não se encontram mais segregadas, o que significa que abrimos um espaço novo em que é imprescindível compreender como tecnologias como o iPad potencializam processos cognitivos.

Enquanto resultado desta pesquisa, nossos esforços caminham na direçáo da transformação das formas como habitamos este mundo que já sabemos se produz com o que fazemos na linguagem. A experiência envolve atos de linguagem de crianças com transtorno global de desenvolvimento, mais de perto o autismo, em ambientes sensíveis organizados com objetos e aplicativos que potencializam o exercício de autoria. As produçóes das crianças implicam na reconstrução contínua do modo de estar neste mundo, na tessitura de pontos de uma rede em que podem se conectar consigo mesmas e com os outros, processos estes que são perturbadores, na medida em que operam transformaçôes na convivência.

\section{Referências}

Atlan, H. (1992). Entre o cristal e a fumaça. Rio de Janeiro: Zahar.

Atlan, H. (2006). Entre resignation et illusion de toute-puissance. In C. Gardeau, \& J. Kristeva (Orgs.). Handicaps: Le temps des engajements. Paris: Ed. PUF.

Damásio, A. (2000). O mistério da consciência. São Paulo: Companhia das Letras.

Damásio, A. (2003). Looking for Spinoza. London: Harcourt.

Deleuze, G. (1992). Espinosa - Uma filosofia prática. São Paulo: Escuta.

Deleuze, G., \& Guatarri, F. (1996). Mil platôs: capitalismo e esquizofrenia, v. 1. São Paulo. Ed 34.

Derrida, J. (2001). Papier machine. Paris: Galilée.

Espinosa, B. (2007). Ética. São Paulo: Abril.

Goody, J. (2007). Pouvoirs et savoirs de l'écrit. Paris: Editions La Dispute.

Guattari, F. (1992). Caosmose. São Paulo: Ed. 34.

Kastrup, V. (1999). A invenção de si e do mundo. Campinas: Papirus.

Kristeva, J. (2001). Au risque de la pensée. Paris: Editions de l'Aube. 
Latour, B. (2000). Jamais fomos modernos. São Paulo: Ed. 34.

Levy, P. (1994). Tecnologias da inteligência. São Paulo: Ed. 34.

Marques, M. O. (1999). A escola no computador: linguagens rearticuladas: educação outra. Ijuí: UNIJUI.

Maturana, H., \& Varela, F. (2001) A árvore do conhecimento: as bases biológicas da compreensão humana. São Paulo: Editora Palas Athena.

Maturana, H., \& Varela, F. (1980). Autopoiesis and cognition. London: Reidel.

Maturana, H., \& Pörksen, B. (2004). Del ser al hacer: los origenes de la biología del conocer. Santiago: J. C. SÁEZ.

Ortega y Gasset, J. (1963). Meditaçâo da técnica. Rio de Janeiro: Ibero-Americano.

Simondon, G. (1989). Du mode d'existence des objets techniques. Paris: Aubier Philosophie.

Simondon, G. (1998). Sobre a tecno-estética: carta a Jaques Derrida. (trad. Stella Senra). In

H. R. Araújo (Org.). Tecnociência e cultura: ensaios sobre o tempo presente (pp. 253-266). São Paulo: Estação Liberdade.

Thibaud, J. P. (2004). Une approche pragmatique des ambiances urbaines. In P. Amphoux.,

G. Chelkoff, \& J. P. Thibaud (orgs.). Ambiances en débats. Grenoble: Editions A la Croisée. Turkle, S. (1997). Life on the screen. New York: Touchstone.

von Foerster, H. (1996). Las semillas de la cibernética. Barcelona: GEDISA.

\section{Nota}

${ }^{1} \mathrm{O}$ nome do grupo e a instituição a que pertence não será explicitado aqui para não causar problemas de identificação. Na versão final do artigo será divulgado.

Recebido em 02 de agosto de 2012 Aceito para publicação em 12 de dezembro de 2013 